Submitted to Journal of

American Chemical Society
UCRL-20858

Preprint

C.2

\title{
$x=C, W=$
}

\section{whentrint}

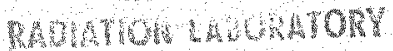

\section{2}

WBQREY AND

DocunENTS SECTION

ORBITAL SYMMETRY CONTROL IN THE

NITRONE-OXAZIRIDINE SYSTEM.

NITRONE PHOTOSTA TIONARY STATES

Janet S. Splitter, Tah-mun Su, Howard Ono, and Melvin Calvin

June 1971

AEC Contract No. W-7405-eng-48

\section{TWO-WEEK LOAN COPY}

This is a Library Circulating Copy which may be borrowed for two weeks. For a personal retention copy, call Tech. Info. Division, Ext. 5545

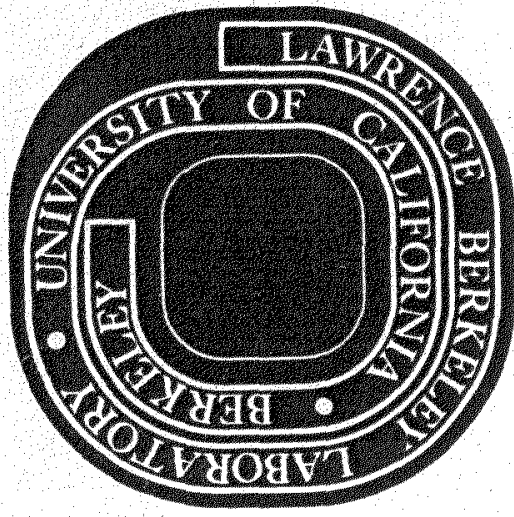


0. vitai Symetry Control in the Nitrone-Oxaziridine Syster.

Nitrone Photostätionäry States

Sir:

Scantly the orbital symmetry rules' have been shown to apoly to teteroato.i. syszoms such as nitrone thernal cycioaddition reactions ${ }^{2}$ and the therma? and jotochemical aziridine ring cleavage at the $C-C$ bond. ${ }^{3}$ The concertec photouyc? zation is disrotatory and the reverse themel cleavage is conrouatcry in trase mocures with four $\pi$ electrons.'

in contrast to the azonethine ylide - aziridine system, the suereochenistry of zis nisrone photocyclization to oxaziridine can only be observed on cartor. aro rizrogen atoms because the oxygen atom has lone pair cectrons insteas of substituents. For the reverse thermal ring opening of oxaziridise to the nitrone, the two possible conrotatory motions of $\mathrm{C}-0$ bond cleavage shou?c resui: ir a mixture of the cis and trans-isomers of the nitrone, ${ }^{4}$ in ccrarsst to the pruscoiosure which should be stereospecific.

zayc $E z \mathrm{al}^{5}$ recently reported the formation of mixtures of cis anc treas axcatidines from the irradiation of trans-nitrones. Honever, there bas zeen zome evidence for the stereospecific formation of oxaziridine from nizns. o. le wish to report our results obtained from the photolysis of severi. nitoros at $-60^{\circ} \mathrm{C}{ }^{7}$ including IIIA and IVA which were studies by 3ayd, Et is. ${ }^{j}$ ar com temperature, and the thermolysis of IB at $-8^{\circ} \mathrm{C}$. Uncer chese

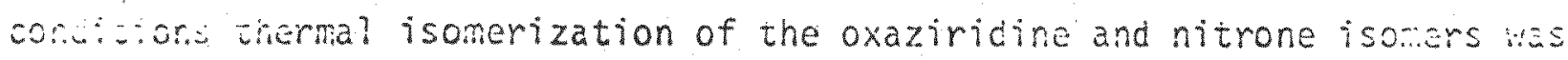

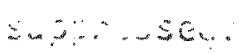




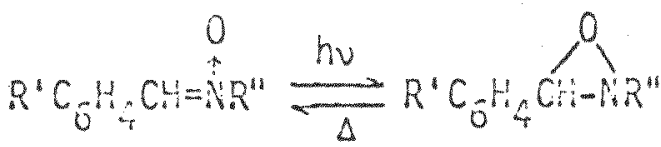

A
B

$$
\begin{aligned}
& \text { I. } R^{\prime \prime}=\left(\mathrm{CH}_{3}\right)_{2}, \mathrm{~B}^{\prime \prime}=\mathrm{CH} \\
& \text { II, } R^{3}=H, R^{n}=C H \\
& \text { III, } R^{3}=10_{2}, R^{n}=C \div 3 \\
& \text { IV, } R^{\prime}=\mathrm{NO}_{2} \cdot \mathrm{R}^{\mathrm{B}}=\mathrm{Cr} \mathrm{CH}_{2}
\end{aligned}
$$

The nur spectra of these nitrones at $-60^{\circ}$ indicated the prescice of only one nitrone isomer, the trans configuration as discussec by kojano anci suzuki. $\$$ Irradiation of trans-IA and IIA at $-60^{\circ}$ in $C D_{3} C D$ arc COCiz yie?ded exclusively trans-oxaziridines," as cbserved by nmr at - -úc. However, under the same conditions in $\mathrm{CD}_{3} \mathrm{CD}$, trans-IIIA and IVA y:e?CEC a nixture of $69 \%$ cis: $31 \%$ trans oxaziridines, which was in cortrast to the predominantly trans-oxaziridines found by Boyd, et al. 5 yto successive partial irradiations of trans-IVA at $-60^{\circ}$, the presence of cis- I/r was comonstrated by nmr, 10 ard a photostationary state of $37 \%$ cis: trans-IVA was reached at approxinately $15 \%$ conversion to oxaziricisez. The cis-IVA rapidly isomerized themaliy to trans-IVA at room temoerazure. The thamal stabjlity of cis-IIIA and IVA was found to be concentrazich deperdent. They were relatively stable when fomed by irraciation at

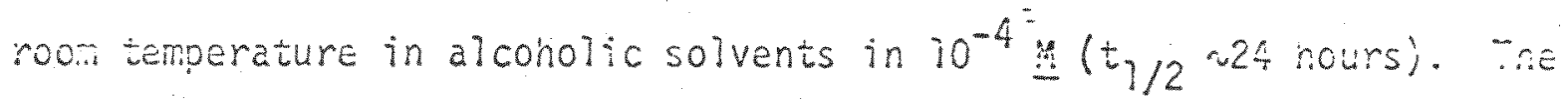
UV apectrum of the photostationary nixture of IVA was similar to trat obaired by dilution of the concentrated solution irradiated in are mir whe to the photostationary state at $-60^{\circ}$. The uv spectrum of cis-1: ?: Was detemined from the photoequilibrim composition and the isostestic point for cis $\rightarrow$ trans themal isomerization.

The ratio of cis and trans-IVA at the photostationary staze is vay - irerent from the ratio of cis and zrans-ivs formed at the sad o: $=$ frococycization reaction. For this reason the quatum yielce of wa

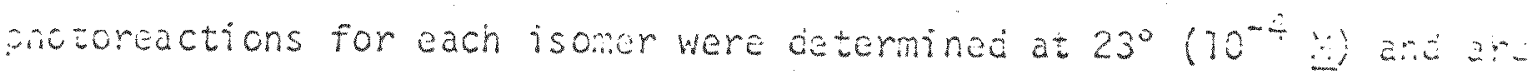


riported in Table I. From the quantum yields of formation of trans and Iabia I. Quantum Yields for produets at $23^{\circ}$ a

\begin{tabular}{|c|c|c|}
\hline Raaction & Solvent & 2 \\
\hline trans-IA $\rightarrow$ trans-1B & iscpropanol & 0.25 \\
\hline $\pm n a s-I V A-I V B^{b}$ & methanol & 0.52 \\
\hline trans-IVA $\rightarrow$ cis-IVAC & $"$ & 0.22 \\
\hline cis-IVA $\rightarrow$ trans-IVAd & i. & 0.57 \\
\hline CIS-IVA $\rightarrow I V B^{b}$ & $"$ & 0.9 \\
\hline
\end{tabular}

a.:ivelength, $366 \mathrm{~nm}$; concentration, $10^{-4}$ M; ferrioxalate actrocmetry. betermined by decrease in optical density at $327 \mathrm{~nm}$, isosbescic poin of the nitrone isoners. CDetermined by change in ratio of opacica sensity at $357 \mathrm{~nm}$ and $317 \mathrm{~nm}$. Calculated from the photostationary state relation, $\phi_{t \rightarrow c} \varepsilon_{t} X_{t}^{\infty}=\phi_{c \rightarrow t} \varepsilon_{c} X_{C}^{\infty}$, where $X_{t}^{\infty}$ and $X_{c}^{\infty}$ are the mo fracticns of the isomers at photoequilibrium.

cis-IVA ${ }^{12}$ and of IVB formation from cis and trans-IVA, the caicuiated ratio of IVB isomers formed after the photostationary state vas resced, assuming stereospecificity is 68\% cis: $32 \%$ trans. After the IV protostitionary state was reached on irradiation at $-60^{\circ}$, the rasio 0 : 110 iscrors found by nmr was $71 \%$ cis: 29\% trans. Therefore, these resuizs ircicate stereospecificity in the nitrone photocyclization rascaco.

For the reverse thermal cleavage of oxaziricine to ritra: 15. OD jo gave a 50:50 mixture of cis and trans-IA with a first oras: rase

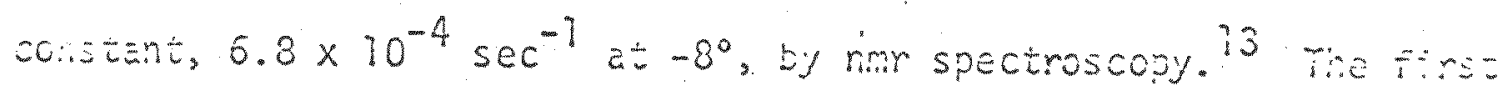
orwer rate constent for the cis $\rightarrow$ thans-IA uncer these condtions in $2.5 \times 10^{-5} \mathrm{sec}^{-1}$ at $23^{\circ}$. Oniy in aicoholic solvents was the rato jo 
ti:e themal cis + trans-IA isomerization slower than the rate of the 20 ring opening reaction. ${ }^{14}$ The photostationary state composition of If was confirmed to be $100 \%$ trans-IA.

The trans-IB thermal clcavage to cis and trans-iA is cicarly in accordance with the predictions of the orbital symetry ruics. Tree ciserved stereospecificity in the nitrone photocyclization is corsistent with the symmetry of the nitrone antibonding molecular orbitai. frs the carbon-oxygen o bond forms in disritatory motion, the nitroger. reiybridizes to a lone pair $s \mathrm{p}^{3}$ hybridized orbital in the cppesite direction, giving an oxaziridine with the same configuration as the initial nitrone.

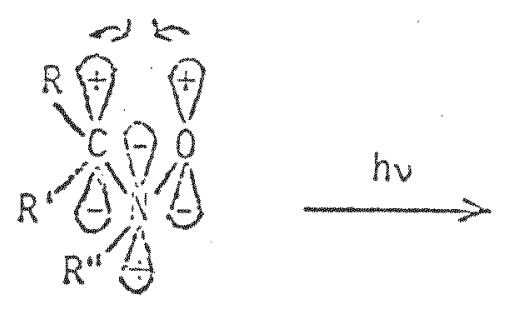<smiles>[R]C1([R])O[Si]1([R7])O</smiles>

Janet S. Splitter, Tah-Hun Su, Howard Ono and Melvia Cäbin Department of Chemistry and Laboratory of Chemicai Btocynamics University of California, Berkeley, Calitomia, S4720 


\section{References and Footnotes}

(1) R. B. Woocivard and R. Hoffman, "The Conservation of Orbita? Symutury," Acazumic Press, Now York, 1909.

(2) R. Guisgen, H. Scidt, and I. Ertring, Chem, Eer, 102, 1102 (:SEs).

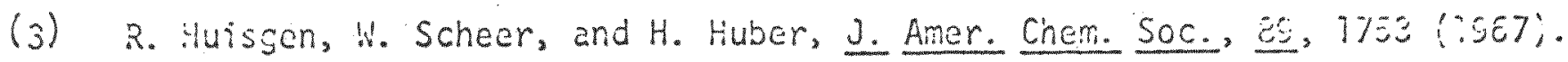

(4) J. S. Splitter and M. Calvin, J. Gra. Chem., 30, 3427 (19E5). fr. ckiziridine was found to cleave at least partially to a cis-nitrore.

(5) D. R. Boyd, W. Jennings, and R. Spratt, Chem. Comman, 745 ( .976 ).

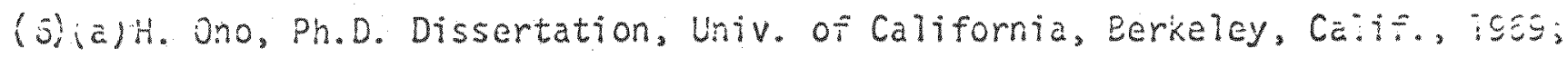

(:s) G. G. Spence, E. C. Taylor, and 0. Buchardt, Chem. Rev., 70, 23: $1: 270)$.

(7) Solutions $\left(70^{-2} \mathrm{M}\right)$ were irradiated in the nmr tube in the prescrice $0:$ oxygen with a Hanovia 450 watu medium pressure mercury lamp. jyrex tizer. The oxaziridines ramained unchanged under these conditions of irracistion. ivir spectra were recorded on a Varian $220 \mathrm{MHz}$ spectrophotometer; uv sjectra on a Cary 14 spectrophotometer.

(S) K. Koyano and H. Suzuki, Tetraiedron Lett., 1859 (1968); 2u1?. Chem. Sos. Jes., 42, 3305 (1969). These authors presented nmr evidence which was used to distinguish cis and trans-nitrone isomërs.

(9) According to the assignment of D. Jerina, D. Boyd, L. Paolilic, anc E. Eccher, Jetrahedron Lett., 1483 (1970).

(10) TrES-IVA: $\alpha-\mathrm{CH}, \tau 7.82 ;-\mathrm{CH}_{3}, \tau .49(\mathrm{t})$

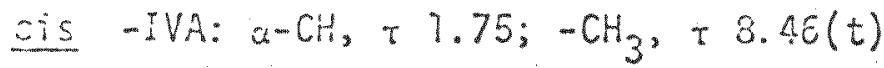

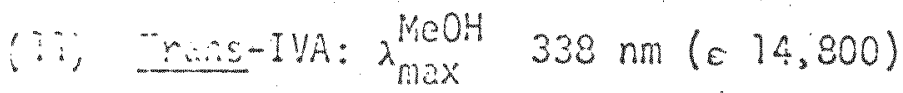
Cic -IVA: $\lambda_{\max }^{\mathrm{MeOH}} 325 \mathrm{~nm}(\varepsilon$ 13,750).

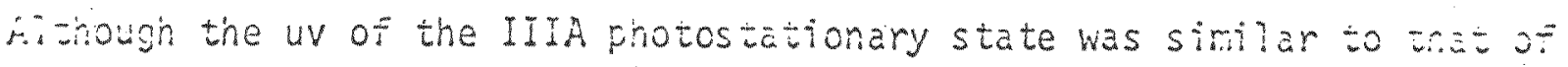

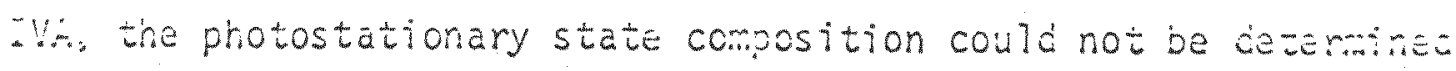
Decause of the lesser solubitizy $0=$ IIIA in $\mathrm{CD}_{3} \mathrm{OD}$. 
(in) The combined $\beta_{t-r}$ and $\phi_{c+t}$ suggest, in addition to oxaziridice formation, the afficient formation of a common twisted state analogous to the zuristed state in the stilbene direct photoisomerization. (a) j. Cugiou, …‥ Ruszkat, and E. Fischer, J. Amer. Chem. Soc., 90, 3907 (1902); (b) J. Saltiel and E. D. Megarity, ibid., 91, 1265 (1969); 90, 4759 (3968).

(13) TM.S-IA: $\alpha-\mathrm{CH}_{2}+2.19 ; \mathrm{N}-\mathrm{CH}_{3},+6.27$. Cis -IA: $\alpha-\mathrm{CH}_{3}, \mathrm{~T} .94 ; \mathrm{N}-\mathrm{CH}_{3}, \tau 6.15$. 10 cis-IA was detected in the partial irradiation of trans-if.

(i4) At $23^{\circ}$ in isopropanol $\left(10^{-4} \mathrm{M}\right)$ the ring cleavage rate was $3.4 \times 10^{-4} \mathrm{sec}^{-i}$; the cis + trans-IA thermal rate was $4.0 \times 10^{-7} \mathrm{sec}^{-1}$. 